\title{
A Simple and Rapid HPLC-PDA MS Method for the Profiling of Citrus Peels and Traditional Italian Liquors*
}

Authors

Affiliation
Clizia Guccione, Maria Camilla Bergonzi, Vieri Piazzini, Anna Rita Bilia

University of Florence, Department of Chemistry, Sesto Fiorentino, Via Ugo Schiff 6, 50019, Florence, Italy
Key words

- Citrus peels and preparations

- flavanones

- flavones

polymethoxyflavones

- protoalkaloids

- HPLC-PDA MS received February 17, 2016

revised May 3, 2016

accepted May 4, 2016

Bibliography

DOI http://dx.doi.org/

10.1055/s-0042-108735

Published online June 9, 2016

Planta Med 2016; 82:

1039-1045 @ Georg Thieme

Verlag KG Stuttgart · New York .

ISSN 0032-0943

Correspondence

\section{Clizia Guccione}

Department of Chemistry

University of Florence

via Ugo Schiff 6

50019 Sesto Fiorentino

Florence

Italy

Phone: + 390554573709

clizia.guccione@unifi.it

\section{Abstract}

$\nabla$

A chromatographic method for the qualitative and quantitative characterization of peels and preparations based on different species of Citrus was developed in order to obtain a complete profile of the constituents, including flavonoids and protoalkaloids. Commercial peels of sweet orange, lemon, mandarin, and grapefruit were analyzed. Seventeen constituents including flavanones, flavones, polymethoxyflavones, and protoalkaloids were identified by HPLC-PDA, HPLC-MS, and HPLC-MS/MS using a comparison of retention times and UV-Vis and MS spectra with reference standards and literature data. The total amount of flavanones [neoeriocitrin (5), naringin (8) and

\section{Introduction}

$\nabla$

The genus Citrus (Rutaceae) represents the largest sector of the world's fruit production, with more than 100 million tons produced each season, among which the major commercially important orange fruit accounted for almost 45 million tons. Around $34 \%$ of these products are used for juice production, yielding large amounts of peels (roughly half of the fruit mass), which represent a source of molasses, pectin, and essential oil. The waste material is usually dried and sold as cattle feed, mixed with dried pulps [1]. Citrus peels have recently been considered potential sources of polyphenols, in particular polymethoxyflavonoids and flavanones (mainly glycosides), due to their potent antioxidant, antiinflammatory, antithrombogenic, antiatherogenic, and hypolipidemic/hypoglycemic effects [2-

\footnotetext{
* Dedicated to Professor Dr. Dr. h.c. mult. Kurt Hostettmann in recognition of his outstanding contribution to natural product research.
}

hesperidin (9)] and polymethoxflavones [sinensetin (12), nobiletin (14), 3,5,6,7,8,3',4'-heptamethoxyflavone (15), and tangeretin (16)] was determined and expressed as naringin (8) or hesperidin (9), and sinensetin (12), respectively. The protoalkaloid synephrine was detected in all samples, except in grapefruit, but its content was lower than the limit of quantification. Qualitative and quantitative chemical profiles of three different Italian aromatic liquors ("Limoncello", "Arancello", and "Mandarinetto"), prepared according to traditional recipes, were also analyzed.

Supporting information available online at http://www.thieme-connect.de/products

11]. Additionally, polymethoxyflavonoids have antiproliferative activity [12-16].

Other characteristic constituents of Citrus peels are phenolic acids and protoalkaloids, principally represented by $p$-synephrine and $p$-octopamine, which are weak adrenergic agonists, active on both $\alpha$ - and $\beta$-adrenoceptors, but orders of magnitude less active than norepinephrine [17]. Protoalkaloids have been involved in the last decade in safety issues. Several reports of adverse effects due to the use of bitter orange as a replacement for ephedra in weight-loss dietary supplements have recently emerged, speculating that synephrine and/or octopamine can increase cardiac output and blood pressure [18]. Consequently, EFSA (European Food Safety Authority) has set a maximum limit for the daily intake of $6.7 \mathrm{mg}$ of synephrine in food supplements [19]. Accordingly, developed analytical methods are mainly focused on the identification of the constituents of bitter orange (Citrus aurantium L.).

At the same time, in many regions of the world, other Citrus peels are used for relieving stomach upset, inflammatory syndromes, and infections 
[13]. In Italy, Citrus peel alcoholic preparations originally developed by Italian monks during the thirteenth and fourteenth centuries as a medicinal drink to treat and/or prevent illnesses have recently evolved into more palatable liquors as aperitifs and after-dinner digestives. However, most of them are merely flavored products made with pure essential oils or commercial essences rather than an infusion of Citrus peels according to the original recipe. The quality control of aromatic herbal liquors is mainly based on the physicochemical properties, from the alcoholic grade, $\mathrm{pH}$, etc., till the assessment of the volatile fraction chemical composition [20-22].

In the current European Pharmacopoeia, there are several monographs on Citrus peels and their preparations (i.e., fluid extract, tincture, syrup), but the quality is generally related to the volatile oil content [23-25]. Only the monograph "Mandarin epicarp and mesocarp" includes a quality control based on flavonoids, in particular on the content of a flavanone glycoside (minimum 3.5 per cent of hesperidin) [26].

Up to now, several analytical methods have been developed for the quantification of phenethylamine alkaloids (e.g., synephrine, octopamine) in Citrus peels and fruits, extracts thereof, and food supplements; most of them use chromatographic (HPLC, GC) and electrophoretic (CE) determinations [27]. Methods have also been developed for the simultaneous characterization of protoalkaloids and organic acids [28], flavanones and protoalkaloids [29], flavanones, hydroxycinnamic acids, and protoalkaloids [30], both polymethoxyflavonoids and flavanones [31], or hydroxycinnamates and polymethoxylated flavones [7].

In this study, we developed a simple and rapid HPLC-PDA and HPLC-MS/MS method suitable for simultaneous qualitative and quantitative analysis of flavones, flavanones, polymethoxyflavones, and protoalkaloids in Citrus peels and to obtain a full polyphenol profile of traditional Italian liquors.

\section{Results and Discussion}

$\nabla$

Several commercial Citrus peels (sweet orange, lemon, grapefruit, and mandarin) and homemade traditional liquors obtained by the infusion of lemon, orange, and mandarin peels were analyzed. Different extraction methods such as maceration and Soxhlet extraction were explored, and three extraction solvents, $100 \%$ methanol, $70 \%$, and $80 \%$ ethanol, were compared for extraction efficiency of the targeted phytochemical constituents. The extraction protocols were finally adopted based on the number and intensity of the protoalkaloid and flavonoid peaks that were detected in the HPLC-MS trace. Accordingly, hydroalcoholic solutions were selected for sweet orange, lemon, and grapefruit, while methanol was chosen for mandarin. The extracts were analyzed by HPLC-PDA, HPLC-MS, and HPLC-MS/MS for the qualitative evaluation of the constituents, while the quantification was made by HPLC-PDA. The chromatographic conditions were selected to obtain chromatograms with optimal resolution of the adjacent peaks. As the stationary phase, two columns, Zorbax ${ }^{\circledR}$ Eclipse XDB-C18 $(4.6 \times 150 \mathrm{~mm}, 5 \mu \mathrm{m})$ and $\mathrm{Vydac}^{\circledR} \mathrm{C}_{18}(4.6 \times$ $250 \mathrm{~mm}, 5 \mu \mathrm{m})$, were evaluated, and the first one that showed the best performance was selected. Formic acid was used as a mobile phase modifier since it significantly reduced the peak tailing of the polyphenols and alkaloids in our experiments. Moreover, gradient elution was used to achieve a better separation of the constituents. Under the optimum gradient conditions reported in the Material and Methods section, a baseline separa- tion of all target peaks was achieved. The PDA wavelengths were set at 240, 280, 330, and $350 \mathrm{~nm}$. MS data of flavones, flavanones, and polymetoxyflavones were recorded in the negative and positive ionization modes while the alkaloids were analyzed only in the positive ion mode. Selected ion monitoring (SIM) was employed to identify the target components. Individual monitored ions are summarized in $\bigcirc$ Table 1. Flavanones and polymethoxyflavones were quantified by HPLC-PDA using an external standard method (see Material and Methods). Limit of detection (LOD) and limit of quantification (LOQ) were $2.46 \mathrm{ng}$ and $12.30 \mathrm{ng}$, respectively, for synephrine, $1.00 \mathrm{ng}$ and $7.67 \mathrm{ng}$ for naringin, $1.32 \mathrm{ng} 9.86 \mathrm{ng}$ for hesperidin, and $1.78 \mathrm{ng} 10.70 \mathrm{ng}$ for sinensetin.

The results of the qualitative analysis of sweet orange peels are reported in Table 1. Ten compounds were identified and their structures are shown in 0 Fig. 1. Fig. 2 presents the TIC chromatograms in positive and negative ion modes. Vicenin-2 (2; MW 594; Rt: $13.0 \mathrm{~min}$ ) gave a $[\mathrm{M}-\mathrm{H}]^{-}$ion at $\mathrm{m} / z$ 593.4. For further confirmation, this ion was subjected to MS/MS investigation to produce secondary fragments $\left\{m / z 575[(\mathrm{M}-\mathrm{H})-18]^{-}, 503\right.$ $\left.\left.[(\mathrm{M}-\mathrm{H})-90]^{-}, 473[(\mathrm{M}-\mathrm{H})-120)\right]^{-}, 383[(\mathrm{M}-\mathrm{H})-210)\right]^{-}, 353$ $\left.[(\mathrm{M}-\mathrm{H})-240)]^{-}\right\}$, which were in agreement with those previously reported in the literature [32,33]. The compound with $\mathrm{Rt}$ $26.3 \mathrm{~min}(7 ; \mathrm{m} / \mathrm{z} 579.4)$ is a structurally, not fully identified isomer of naringin (8), probably differing from the latter by the nature or location of the sugar residue. The MS/MS analysis of 7 produced the same fragmentation pattern as $8\left\{\mathrm{~m} / \mathrm{z} 579[\mathrm{M}-\mathrm{H}]^{-}\right.$, $\left.\left.\left.459[(\mathrm{M}-\mathrm{H})-120)]^{-}, 313[(\mathrm{M}-\mathrm{H})-266)\right]^{-}, 271[(\mathrm{M}-\mathrm{H})-308)\right]^{-}\right\}$ [34]. However, in contrast to naringin (8) and its strong fragment ion at $m / z 459$, the most abundant fragment was observed at $m / z$ $271.0[(\mathrm{M}-\mathrm{H})-308]^{-}$, resulting from the loss of the disaccharide unit. The peaks at 27.5 and 32.0 min were identified as hesperidin (9) and sinensetin (12), respectively, in comparison with standards. The compound at Rt $29.3 \mathrm{~min}\left(\mathrm{~m} / \mathrm{z} 593.4[\mathrm{M}-\mathrm{H}]^{-}\right)$ was attributed to poncirin (10) from its UV and mass spectra. In fact, even if vicenin-2 (2) also present in sweet orange has the same molecular weight, both compounds could be reliably distinguished by comparison with literature data [31] and from different elution times and MS/MS data. Poncirin (10) gave essentially a fragment ion with $m / z 285.2$, resulting from the cleavage of the glycosidic bond and loss of neohesperidose $(\mathrm{m} / \mathrm{z} 308)$, leaving the aglycone isosakuranetin $\left.\{m / z 285[(\mathrm{M}-\mathrm{H})-308)]^{-}\right\}$. This ion is not observed in the case of vicenin-2 (2) because, in this case, the characteristic fragmentation is due to a ring opening on the sugar moiety. The peak at Rt $30.0 \mathrm{~min}$ is due to three coeluting substances with $m / z 726.6[\mathrm{M}-\mathrm{H}]^{-}, 696.6[\mathrm{M}-\mathrm{H}]^{-}$, and $711.2[\mathrm{M}-\mathrm{H}]^{-}$. Among these, only the peak at $m / z 726.6$ could be identified. It was assigned to citrusin III (11), a cyclic peptide consisting of seven aminoacids (Gly-Ser-Pro-Leu-Leu-Pro-Tyr). The peak at Rt $32.4 \mathrm{~min}$ (13) is an unidentified structural isomer of nobiletin (5,6,7,8,3',4'-hexamethoxyflavone) (14), having the same UV spectrum and fragment ions in the positive ionization mode $\left\{m / z\right.$ 403.3 $[\mathrm{M}+\mathrm{H}]^{+} ; \mathrm{m} / \mathrm{z}: 388.4[(\mathrm{M}+\mathrm{H})-14]^{+} ; 373.3$ $[(\mathrm{M}+\mathrm{H})-30]^{+} ; 355.4[(\mathrm{M}+\mathrm{H})-48]^{+} ; 313.5[(\mathrm{M}+\mathrm{H})-90]^{+} ; 151.2$ $\left.[(\mathrm{M}+\mathrm{H})-151]^{+}\right\}$. Nobiletin (14) was identified at $33.8 \mathrm{~min}$. Finally, the peak at $\mathrm{Rt} 33.2 \mathrm{~min}$ corresponded to 3,5,6,7,8,3',4'-heptamethoxyflavone (15) [33], while that at $\mathrm{Rt} 33.6 \mathrm{~min}$ was found to be tangeretin (16) [33].

In the lemon peel, 11 compounds were identified ( $\bullet$ Table 1 ). - Fig. 3 shows the positive and negative TIC chromatograms. The peaks at Rt 13.0 (2), 26.3 (7), 27.5 (9), 32.9 (14), 33.3 (15), and 33.7 (14) min correspond to compounds already identified 


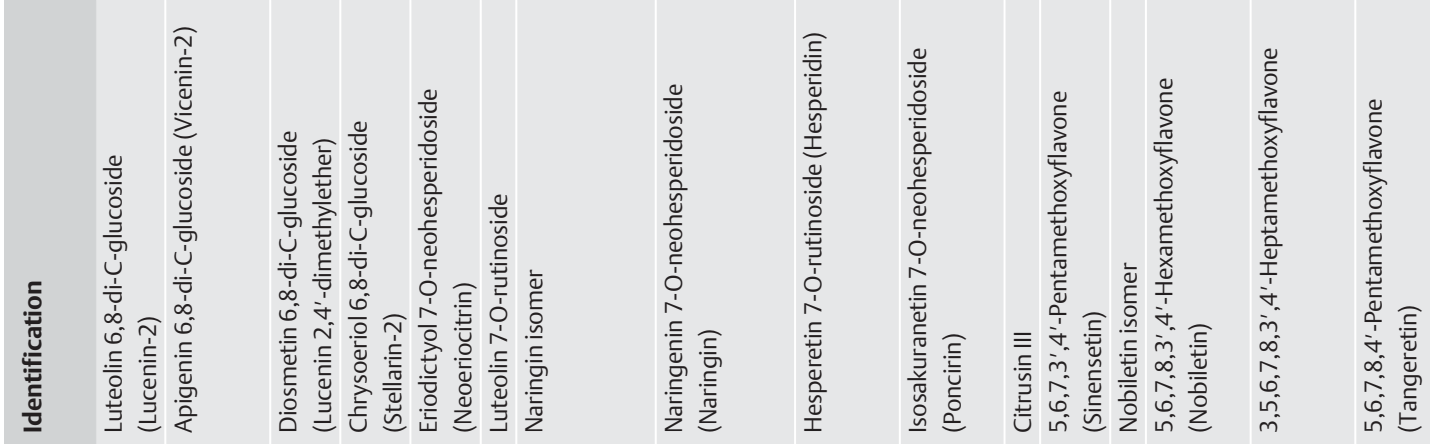

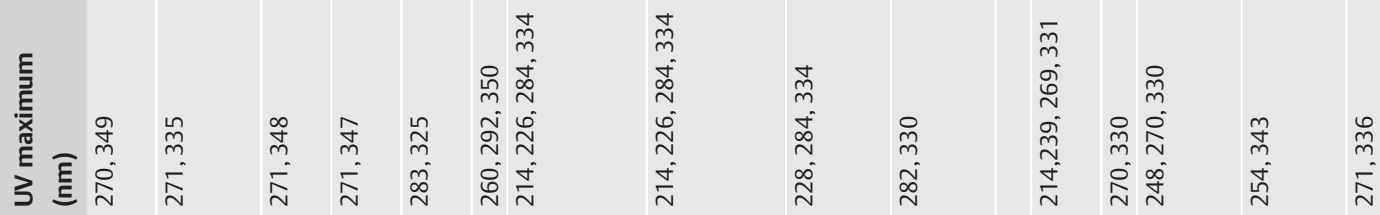

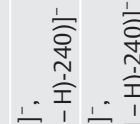

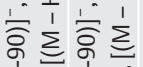

金主m

,

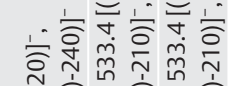

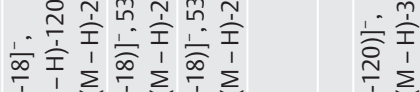

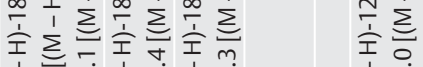

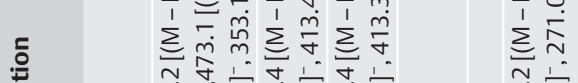

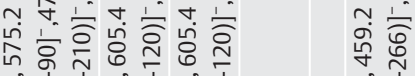

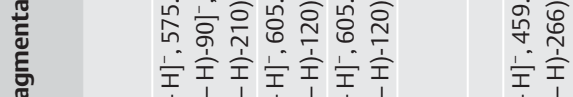

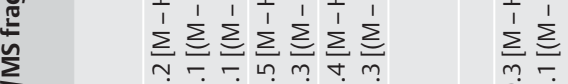

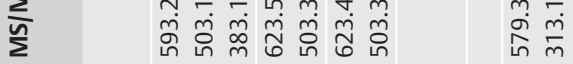

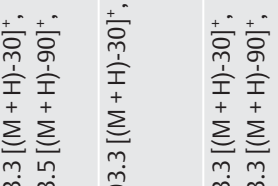

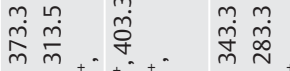

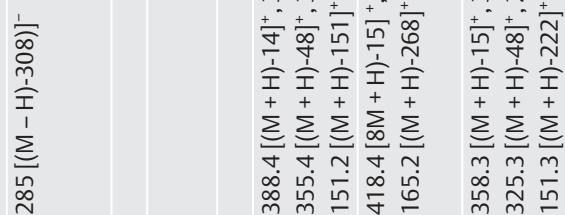

产 $\frac{1}{6} \frac{1}{0}$

宔产全塞主

主主主主完完主

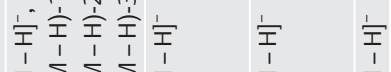

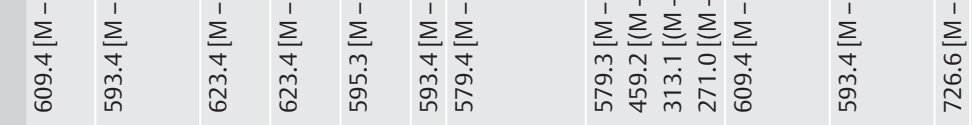
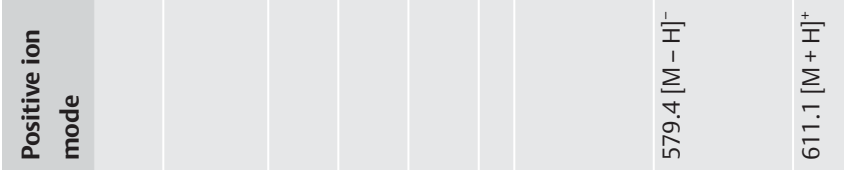

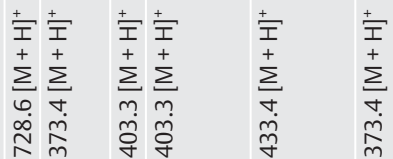

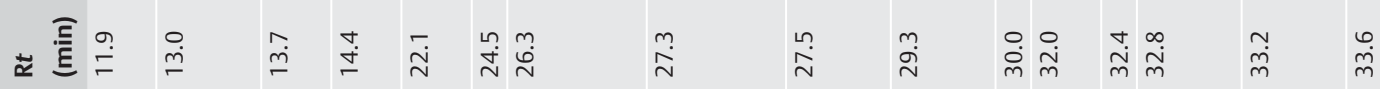

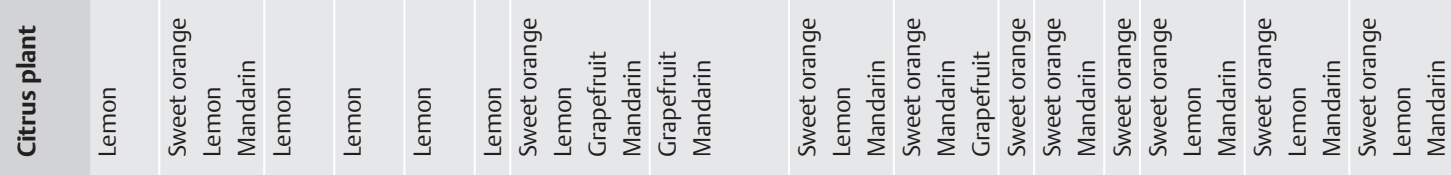

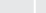

$+2$

r m 
in the sweet orange peels. Lucenin-2 (1) (Rt: 11.9 min) was identified by MS/MS analysis. Lucenin-2 generated a quasi-molecular ion at $m / z 609.4\left[(\mathrm{M}-\mathrm{H})^{-}\right]$. Fragments were detected at $m / z 591$

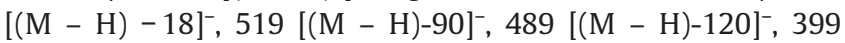
$[(\mathrm{M}-\mathrm{H})-210]^{-}$, and $\left.369[(\mathrm{M}-\mathrm{H})]^{-} 240\right]^{-}[33]$. The identity of lucenin-2 4'-methylether (3) (Rt: $13.7 \mathrm{~min}$ ) was confirmed by the characteristic MS and MS/MS data and the retention time [32, 33]. The peak at Rt 14.4 min corresponded to stellarin-2 (chrysoeriol 6,8-di-C-glucoside) (4) and was confirmed by UV and MS data [34]. The substance at Rt: $22.1 \mathrm{~min}$ was identified as neoeriocitrin (5). In the MS/MS spectrum, three ions were present at $\mathrm{m} / \mathrm{z} 595.3[\mathrm{M}-\mathrm{H}]^{-}, 459[(\mathrm{M}-\mathrm{H})-136]^{-}$, and 287.2 $[(\mathrm{M}-\mathrm{H})-308]^{-}$. The main fragment at $\mathrm{m} / \mathrm{z} 287.2$ corresponded to the aglycone eryodictyol, resulting from the loss of the disaccharide neohesperidose. Literature data [33] report that neoeriocitrin (5) (a neohesperidoside) is able to form the fragment $\mathrm{m} / \mathrm{z}$ 459 [( $\mathrm{M}-\mathrm{H})-136]^{-}$that is not observed for the isomer eriotricin (a rutinoside), which presents a same UV spectrum. The loss of a fragment of $m / z 136$ may correspond to a retro-cyclization that involves the aglycone.

In the grapefruit peel, three peaks have been identified ( Table 1). The TIC chromatographic traces in the positive and negative modes are shown in $\odot$ Fig. 4. At Rt $26.3 \mathrm{~min}$, the naringin isomer $\mathbf{7}$ was identified, while naringin (8) was detected at Rt $27.3 \mathrm{~min}$, and poncirin (10) at Rt: $29.3 \mathrm{~min}$.

In the mandarin peel, nine flavonoids were identified and are reported in $\odot$ Table 1. All compounds were also found in previous samples and their structures have been identified as described above. O Fig. 5 shows the positive and negative TIC chomatograms.

Detection of the alkaloid synephrine in the four samples was performed by HPLC-MS and HPLC-MS/MS. The comparison of the TIC in the positive ion mode of all Citrus species is shown in ๑ Fig. 6. Synephrine was identified by comparison of its retention time and mass spectra with those of the reference standard $\left([\mathrm{M}+\mathrm{H}]^{+}\right.$ $\mathrm{m} / \mathrm{z}$ 168). Its content was, however, below the LOQ in the HPLC-PDA analysis (detection at $280 \mathrm{~nm}$ ). Synephrine was detected in mandarin, sweet orange, and lemon commercial peels, but not in grapefruit, which is consistent with a previous report [35].

Flavonoids were quantified in peels and liquors. Hesperidin (9) was used as a reference standard for the quantification of all flavanones in the sweet orange extract, while naringin (8) was employed for lemon, grapefruit, and mandarin samples. Polymethoxyflavones in all samples were quantified and expressed as sinensetin (12). The data are reported in O Table 2.

Sweet orange peels are the richest matrix in polymethoxyflavones, while the highest content of flavanones was found in grapefruit peels. The percentage of flavanones in the lemon and mandarin samples are similar, but mandarin contains more polymethoxyflavones than lemon peels.

HPLC-PDA analyses were also performed to obtain qualitative and quantitative polyphenol profiles of the liquors. A high content of flavanones, mainly glycosides, was found in the investigated preparations. Thus, in $40 \mathrm{~mL}$ (typical glass) of Arancello, there were $15.8 \mathrm{mg}$ of flavanones expressed as hesperidin, while $22.0 \mathrm{mg}$ were found in the same volume of Mandarinello, and $39.6 \mathrm{mg}$ in Limoncello, the richest liquor. In all preparations, a few milligrams (1-3 mg for a 40-mL glass) of polymethoxyflavones were found. No protoalkaloids were detected in the tested samples.

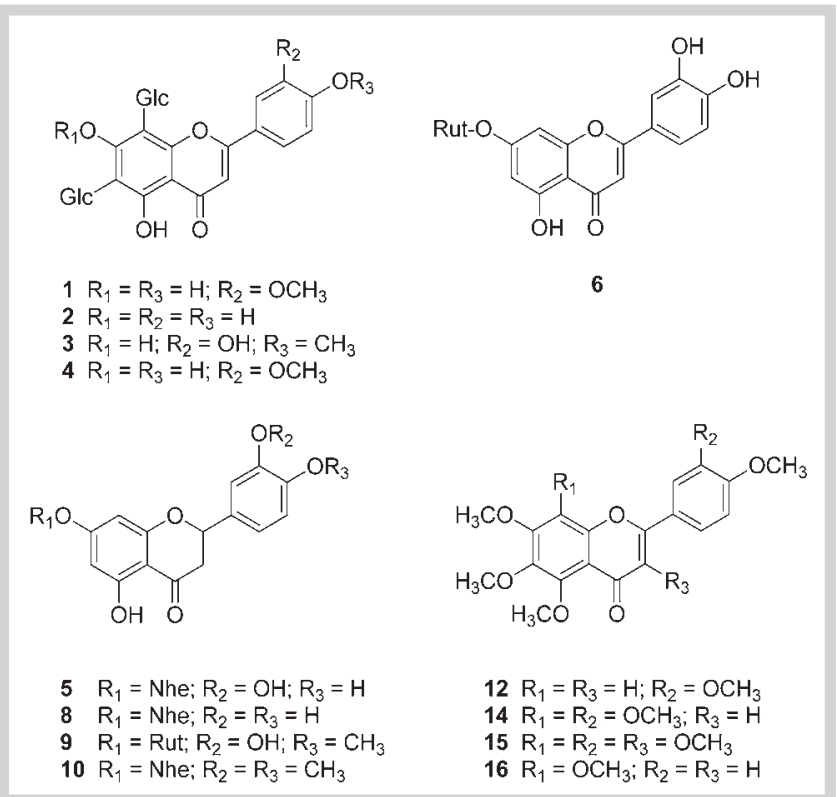

Fig. 1 Structures of identified flavonoids. Glc: glucose; Rut: rutinose; Nhe: neohesperidose.

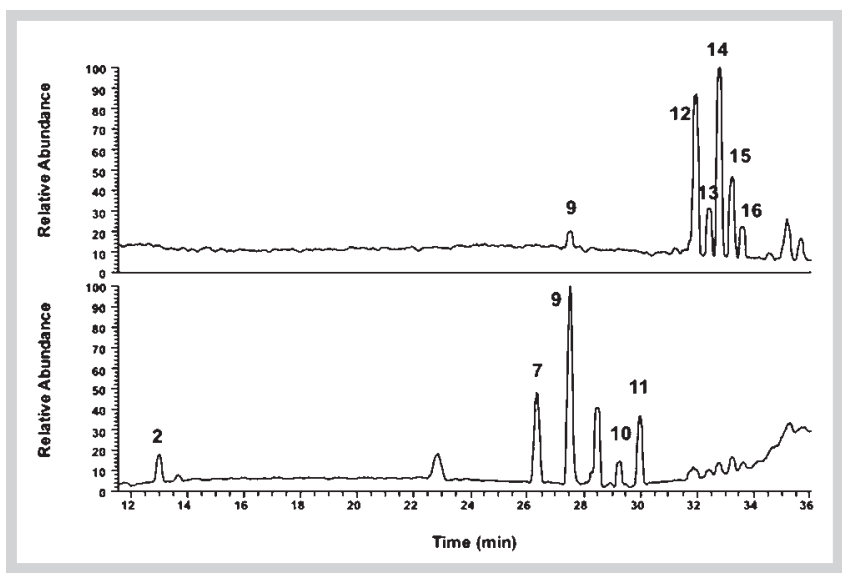

Fig. 2 Total ion current (12-36 min) in positive (top) and negative (bottom) ionization modes of a sweet orange sample.

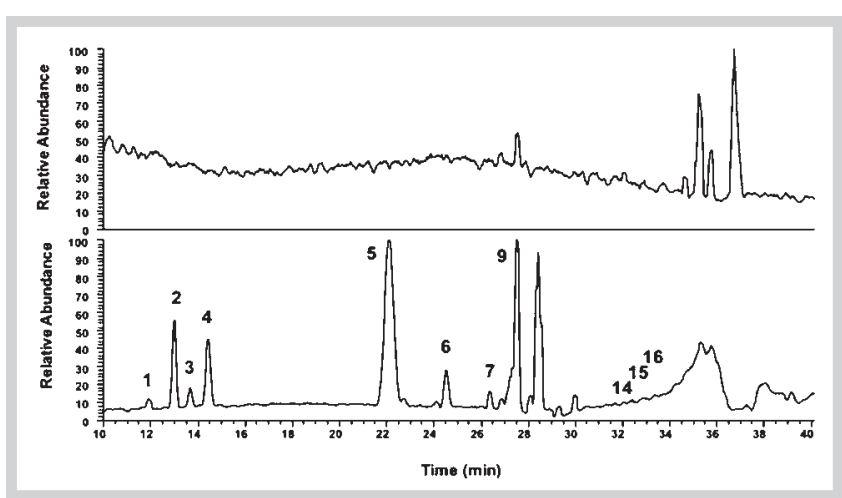

Fig. 3 Total ion current (10-40 $\mathrm{min}$ ) in positive (top) and negative (bottom) ionization modes of a lemon sample. 


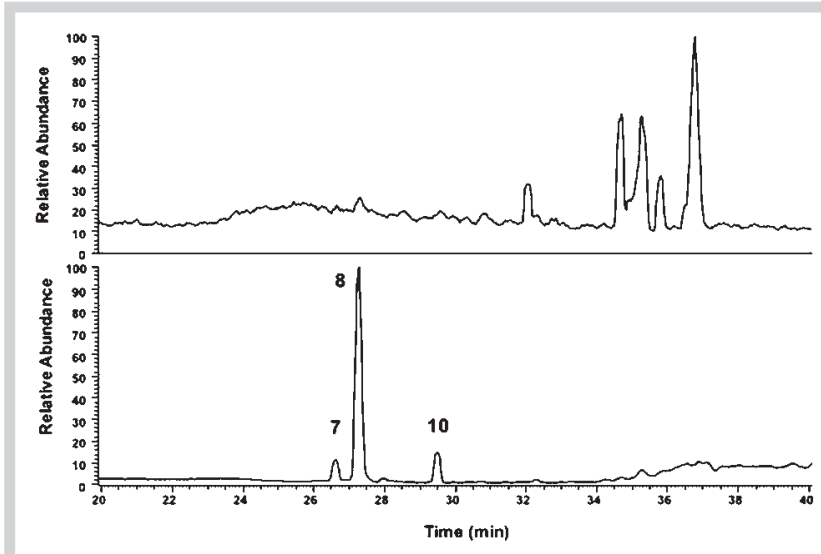

Fig. 4 Total ion current (10-40 $\mathrm{min}$ ) in positive (top) and negative (bottom) ionization modes of a grapefruit sample.

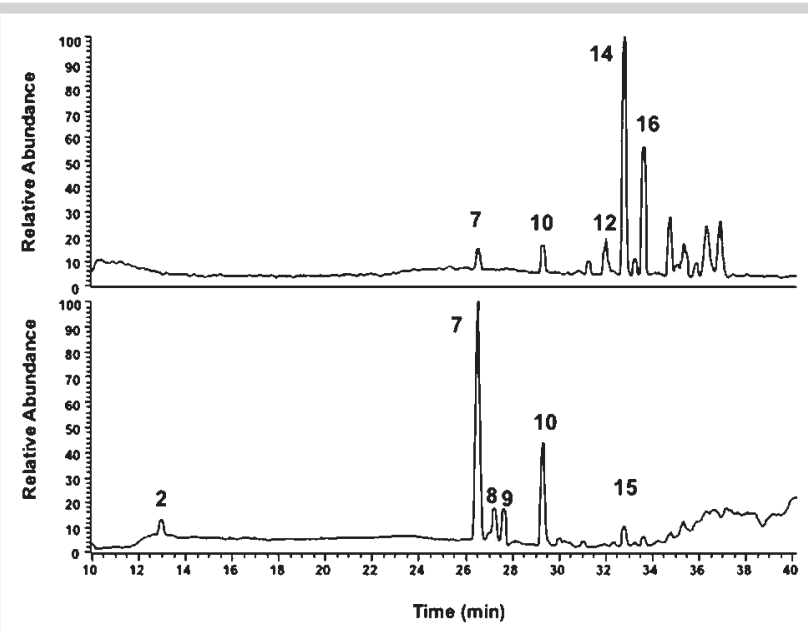

Fig. 5 Total ion current (10-40 min) in positive (top) and negative (bottom) ionization modes of a mandarin sample.

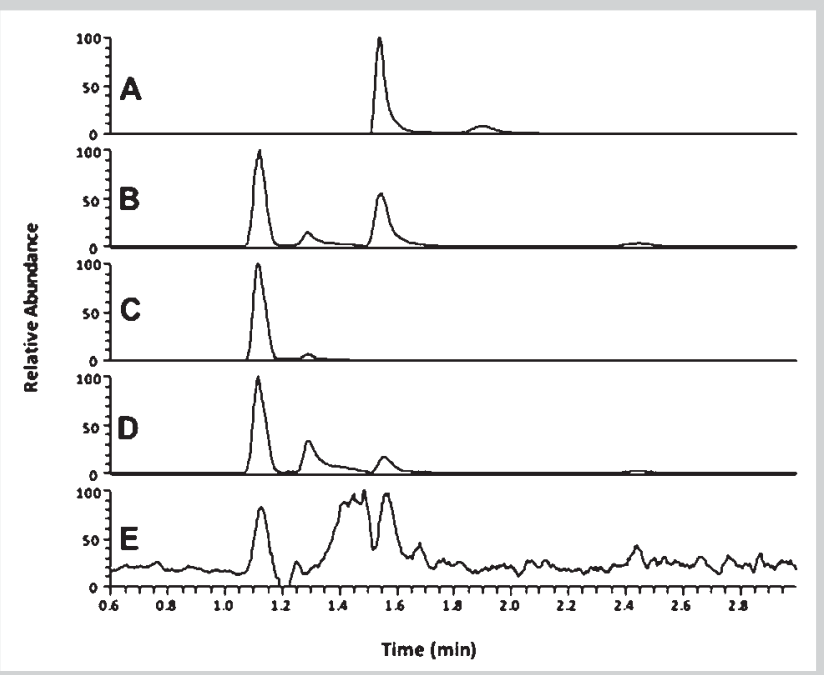

Fig. 6 Total ion current (positive ionization mode) of synephrine standard (A), mandarin (B), grapefruit (C), sweet orange (D), and lemon (E) samples.
Table 2 Content of flavanones and polymethoxyflavones in Citrus peels.

\begin{tabular}{|l|l|l|}
\hline Sample & $\begin{array}{l}\text { \% of Flavanones/ } \\
\text { herbal drug } \\
\text { (expressed as naringin) }\end{array}$ & $\begin{array}{l}\text { \% of Polymethoxyflavones/ } \\
\text { herbal drug } \\
\text { (expressed as sinensetin) }\end{array}$ \\
\hline Sweet orange & $\begin{array}{l}0.79 \% \\
\text { (expressed as hesperidin) }\end{array}$ & $1.30 \%$ \\
\hline Lemon & $4.92 \%$ & $0.05 \%$ \\
\hline Grapefruit & $14.00 \%$ & $0.62 \%$ \\
\hline Mandarin & $3.53 \%$ & $0.60 \%$ \\
\hline
\end{tabular}

In conclusion, the profiles of flavonoids and other constituents such as synephrine were analyzed in the peels of four species of Citrus, Citrus sinensis (L.) Osbeck, Citrus limon (L.) Burm. fil., Citrus paradisi Macfad., and Citrus reticulata Blanco. The main constituents were $O$-glycosylated flavanones [mainly represented by neoeriocitrin (5), naringin (8) and hesperidin (9)], $O$ glycosylated and C-glycosylated flavones [lucenin-2 (1), vicenin2 (2), lucenin-2 4'-methyl ether (3), stellarin-2 (4), and luteolin7O-rutinoside (6)], and polymethoxyflavones [sinensetin (12), nobiletin (14), 3,5,6,7,8,3',4'-heptametoxyflavone (15), and tangeretin (16)]. Protoalkaloids such as synephrine were not detected or were detected under the limit of quantification.

The developed method is applicable to the quality control of Citrus peels and their preparations, including extracts, food supplements, and traditional liquors, in order to support their quality and safety. Some of these liquors are protected by the European regulation forbidding the addition of nature-identical flavoring substances. Consequently, in addition to GC analysis, determination of the profile of the nonvolatile constituents could represent a simple, easy way to perform analysis to guarantee the quality of these traditional liquors.

\section{Materials and Methods}

$\nabla$

\section{Chemicals}

Anaytical grade solvents for extraction and HPLC grade solvents (acetonitrile, formic acid, DMSO and $\mathrm{MeOH}$ ) were purchased from Sigma-Aldrich. EtOH (96\%) was from Riedel-de-Haën Rdh Soherchemikalien $\mathrm{GmbH} \&$ Co. Ultrapure deionized water (18 MX) was obtained through a Milli-Q system (Millipore).

\section{Plant materials}

The peels of $C$. sinensis (sweet orange, lot $n$. CD 16781), C. limon (lemon, lot n. R7146Z), C. paradisi (grapefruit, lot n. R7144Z), and C. reticulata (mandarin, lot $\mathrm{n}$. $\mathrm{R} 7145 \mathrm{Z}$ ) were kindly offered by Amway GmbH.

Citrus liquors were prepared using organic fruits from Tuscany, namely 12 lemon fruits (approx. $1 \mathrm{~kg}$ ) for Limoncello and 20 mandarin fruits (approx. $1.6 \mathrm{~kg}$ ) for Mandarinello, or from Sicily, namely 10 orange fruits (approx. $2 \mathrm{~kg}$ ) for Arancello.

\section{Reference compounds}

Naringin (naringenin 7-0-neohesperidoside, 8), hesperidin (hesperetin 7-0-rutinoside, 9), sinensetin (3',4',5,6,7-pentamethoxyflavone, 12), and synephrine were purchased from Extrasynthèse and used as standards for qualitative and quantitative analyses. Their purity was higher than $98 \%$. 


\section{Extraction and sample preparation}

The methanol extract of the mandarin peels was prepared by maceration of $2 \mathrm{~g}$ of herbal drug with $100 \mathrm{~mL}$ of $\mathrm{MeOH} 100 \%$ (thrice). Hydroalcoholic extracts of lemon and grapefruit peels were prepared by maceration of $2 \mathrm{~g}$ of herbal drugs with $100 \mathrm{~mL}$ of EtOH/ $\mathrm{H}_{2} \mathrm{O} 70: 30$ (thrice), whereas hydroalcoholic extracts of sweet orange peels were obtained by maceration of $2 \mathrm{~g}$ of peels with $100 \mathrm{~mL}$ of $\mathrm{EtOH} / \mathrm{H}_{2} \mathrm{O}$ 80:20 (thrice). After 3 days, the extracts were filtered and evaporated to dryness. Extraction yields were $26.2 \%$ for sweet orange peels, $49.2 \%$ for lemon peels, $45.9 \%$ for grapefruit peels, and $23.1 \%$ for mandarin peels. The dry extracts were solubilized in MeOH/DMSO 4:1, ultrasonicated for $5 \mathrm{~min}$, and centrifuged for $4 \mathrm{~min}$ at $14000 \mathrm{rpm}$ prior to injection into HPLC.

Liquors were prepared in our laboratory, according to traditional recipes. Fruits were accurately peeled out and the skins, consisting of the flavedo parts, were put into $1 \mathrm{~L}$ of $\mathrm{EtOH}$ (96\% vol.) and left to draw for 2 weeks. After this time, lemon, orange, and mandarin peels were taken out of the alcohol, and a syrup made with $1 \mathrm{~L}$ of water plus $800 \mathrm{~g}$ of sugar was added to the ethanolic extract. The liquor obtained was let to rest for a couple of days before being analyzed.

\section{HPLC-PDA and HPLC-MS/MS analyses}

For qualitative analysis, MS and MS/MS experiments were conducted using an HPLC Surveyor coupled to an LTQ equipped with an ESI interface (Thermo Electron). Mass spectrometry and electrospray operating parameters were optimized for negative and positive polarities. The following final settings were used: Sheath gas flow rate (arb): 30, Aux gas flow rate (arb): 9, Sweep gas rate (arb): 5 , Capillary temp. $\left({ }^{\circ} \mathrm{C}\right): 280.00$, Capillary voltage (V): 11.00 , Tube lens (V): 60.00, Normalized collision energy: 25, 20. MS spectra were acquired from $\mathrm{m} / \mathrm{z} 240$ to 100 in negative and positive ion modes.

For quantitative analysis, an HP $1100 \mathrm{~L}$ instrument with a diode array detector controlled by an HP 9000 workstation (Agilent Technologies) was used. Data were processed with HP ChemStation software (Agilent).

Separations were performed at $27^{\circ} \mathrm{C}$ on a Zorbax Eclipse XDB-C18, $(150 \mathrm{~mm} \times 4.6 \mathrm{~mm}, 5 \mu \mathrm{m}$, Agilent). The mobile phase consisted of $\mathrm{H}_{2} \mathrm{O}$ at pH 3.2 adjusted by formic acid (solvent $A$ ), methanol (solvent $\mathrm{B}$ ), and acetonitrile (solvent $\mathrm{C}$ ). The flow rate was $1 \mathrm{~mL} / \mathrm{min}$ and the total run time was $45 \mathrm{~min}$. The following gradient profile was used: $0-10 \mathrm{~min}, 0 \% \mathrm{~B}, 0-15 \% \mathrm{C} ; 10-20 \mathrm{~min}$, 0-10\% B, 15-10\% C; 20-25 min 10\% B, 10-20\% C; 25-35 min, 10$15 \%$ B, 20-75\% C; 35-40 min, 15-10\% B, 75-80\% C; 40-45 min, $10-0 \%$ B $80-0 \%$ C, with an equilibration time of $10 \mathrm{~min}$. The sample-injected volume was $10 \mu \mathrm{L}$. UV spectra were recorded between 200 and $600 \mathrm{~nm}$. Chromatographic profiles were recorded at $240,280,330$, and $350 \mathrm{~nm}$. The identification of the constituents was performed by comparing the retention time and the UV, MS, and MS/MS spectra of the peaks in the samples with those of authentic reference samples or literature data.

\section{Quantification of flavonoids}

Calibration curves: Standard solutions were freshly prepared by serial dilutions of stock solutions in $\mathrm{MeOH} / \mathrm{DMSO} 4: 1$ to obtain the following concentrations: 2.28, 3.43,11.43, 13.71, and $22.85 \mu \mathrm{g} / \mathrm{mL}$ for hesperidin (9), 3.15, 1.89, 1.26, 0.88 , and 0.25 for sinensetin (12), and $14.1,8.46,5.64,3.95$, and $1.12 \mu \mathrm{g} / \mathrm{mL}$ for naringin (8).
Limit of detection and limit of quantification: Serial dilutions of standard solutions were used for determinating the limits of detection ( $L O D ; S / N \geq 3$ ) and limits of quantification (LOQ; $S / N \geq 10$ ). Synephrine, naringin (8), hesperidin (9), and sinensetin (12) were accurately weighed and dissolved in $\mathrm{MeOH}$.

Quantitative determination of constituents: The external standard method was applied. Quantification was performed using regression curves. Measurements were performed at $280 \mathrm{~nm}$ for flavanones and $350 \mathrm{~nm}$ for polymethoxyflavones. Individual peaks of flavanones and polymethoxyflavones were quantified in the HPLC-PDA trace as hesperidin (9) (sweet orange) or naringin (8), and sinensetin (12), respectively. The amounts were then added to obtain the total contents of flavanones and polymethoxyflavones. Results are expressed as the mean of three separate experiments.

\section{Supporting information}

HPLC-UV traces (UV $350 \mathrm{~nm}$ ) for the peel extracts of sweet orange, lemon, grapefruit, and mandarin are available as Supporting Information.

\section{Acknowledgements}

This study was supported by an Amway GmbH Scientific Grant.

\section{Conflict of Interest}

$\nabla$

The authors declare no conflict of interest.

\section{References}

1 Khan MK, Abert-Vian M, Fabiano-Tixier AS, Dangles O, Chemat F. Ultrasound-assisted extraction of polyphenols (flavanone glycosides) from orange (Citrus sinensis L.) peel. Food Chem 2010; 119: 851-858

2 Chen ZT, Chu HL, Chyau CC, Chu CC, Duh PD. Protective effects of sweet orange (Citrus sinensis) peel and their bioactive compounds on oxidative stress. Food Chem 2012; 135: 2119-2127

3 Whitman SC, Kurowska EM, Manthey JA, Daugherty A. Nobiletin, a citrus flavonoid isolated from tangerines, selectively inhibits class A scavenger receptor-mediated metabolism of acetylated LDL by mouse macrophages. Atherosclerosis 2005; 178: 25-32

4 Lin N, Sato T, Takayama Y, Mimaki Y, Sashida Y, Yano M, Ito A. Novel anti-inflammatory actions of nobiletin, a citrus polymethoxy flavonoid, on human synovial fibroblasts and mouse macrophages. Biochem Pharmacol 2003; 65: 2065-2071

5 Huang YS, Ho SC. Polymethoxy flavones are responsible for the antiinflammatory activity of citrus fruit peel. Food Chem 2010; 119: 868873

6 Li RW, Theriault AG, Au K, Douglas TD, Casaschi A, Kurowska EM, Mukherjee R. Citrus polymethoxylated flavones improve lipid and glucose homeostasis and modulate adipocytokines in fructose-induced insulin resistant hamsters. Life Sci 2006; 79: 365-373

7 Kurowska EM, Manthey JA. Hypolipidemic effects and absorption of citrus polymethoxylated flavones in hamsters with diet-induced hypercholesterolemia. J Agric Food Chem 2004; 52: 2879-2886

8 Green CO, Wheatley AO, McGrowder DA, Dilworth LL, Asemota HN. Citrus peel polymethoxylated flavones extract modulates liver and heart function parameters in diet induced hypercholesterolemic rats. Food Chem Toxicol 2013; 51: 306-309

9 Kang SR, Han DY, Park KI, Park HS, Cho YB, Lee HJ, Lee WS, Ryu CH, Ha YL, Lee do H, Kim JA, Kim GS. Suppressive effect on lipopolysaccharideinduced proinflammatory mediators by Citrus aurantium L. in macrophage RAW 264.7 cells via NF-kB signal pathway. Evid Based Complement Alternat Med 2011; 2011: 248592

10 Kim GS, Park HJ, Woo JH, Kim MK, Koh PO, Min W, Ko YG, Kim CH, Won $\mathrm{CK}$, Cho JH. Citrus aurantium flavonoids inhibit adipogenesis through 
the Akt signaling pathway in 3T3-L1 cells. BMC Complement Altern Med 2012; 12: 31

11 Li S, Pan MH, Lo CY, Tan D, Wang Y, Shahidi F, Ho CT. Chemistry and health effects of polymethoxyflavones and hydroxylated polymethoxyflavones. J Funct Foods 2009; 1: 2-12

12 Manthey JA, Grohmann K, Guthrie N. Biological properties of citrus flavonoids pertaining to cancer and inflammation. Curr Med Chem 2001; 8: $135-153$

13 Benavente-García 0, Castillo J. Update on uses and properties of citrus flavonoids: new findings in anticancer, cardiovascular, and antiinflammatory activity. J Agric Food Chem 2008; 56: 6185-6205

14 Yoshimizu N, Otani Y, Saikawa Y, Kubota T, Yoshida M, Furukawa T, Kumai K, Kameyama K, Fujii M, Yano M, Sato T, Ito A, Kitajima M. Antitumour effects of nobiletin, a citrus flavonoid, on gastric cancer include: antiproliferative effects, induction of apoptosis and cell cycle deregulation. Aliment Pharmacol Ther 2004; 20: 95-101

$15 \mathrm{Du} \mathrm{Q}$ Chen $\mathrm{H}$. The methoxyflavones in Citrus reticulata Blanco cv. ponkan and their antiproliferative activity against cancer cells. Food Chem 2010; 119: 567-572

16 Righeschi C, Eichhorn T, Karioti A, Bilia AR, Efferth T. Microarray-based mRNA expression profiling of leukemia cells treated with the flavonoid, casticin. Cancer Genomics Proteomics 2012; 9: 143-151

17 Jordan R, Midgley JM, Thonoor CM, Williams CM. $\beta$-Adrenergic activities of octopamine and synephrine stereoisomers on guinea-pig atria and trachea. J Pharm Pharmacol 1987; 39: 752-754

18 Stohs SJ. Assessment of the adverse event reports associated with Citrus aurantium (bitter orange) from April 2004 to October 2009. J Funct Foods 2010; 2: 235-238

19 EFSA Scientific Cooperation (ESCO) Working Group on Botanicals and Botanical Preparations. Advice on the EFSA guidance document for the safety assessment of botanicals and botanical preparations intended for use as food supplements, based on real case studies on request of EFSA. EFSA J 2009; 7: 280

20 Crupi M, Costa R, Dugo P, Dugo G, Mondello L. A comprehensive study on the chemical composition and aromatic characteristics of lemon liquor. Food Chem 2007; 105: 771-783

21 Schipilliti L, Bonaccorsi I, Cotroneo A, Dugo P, Mondello L. Evaluation of gas chromatography-combustion-isotope ratio mass spectrometry (GC-C-IRMS) for the quality assessment of citrus liqueurs. J Agric Food Chem 2013; 61: 1661-1670

22 Andrea $V$, Nadia $N$, Teresa RM, Andrea A. Analysis of some Italian lemon liquors (Limoncello). J Agric Food Chem 2003; 51: 4978-4983
23 European Pharmacopoeia Commission. Bitter orange epicarp and mesocarp (Aurantii Amari Epicarpium and Mesocarpium). In: European Pharmacopoeia, 7th edition. Strasbourg: Council of Europe; 2011

24 European Pharmacopoeia Commission. Sweet orange oil (Aurantii Dulcis Olii). In: European Pharmacopoeia, 7th edition. Strasbourg: Council of Europe; 2011

25 European Pharmacopoeia Commission. Mandarin oil (Citri Reticulatae Aetheroleum). In: European Pharmacopoeia, 8th edition. Strasbourg: Council of Europe; 2014

26 European Pharmacopoeia Commission. Mandarin epicarp and mesocarp (Citri Reticulatae Epicarpium and Mesocarpium). In: European Pharmacopoeia, 8th edition. Strasbourg: Council of Europe; 2014

27 Pellati F, Benvenuti S. Chromatographic and electrophoretic methods for the analysis of phenethylamine [corrected] alkaloids in Citrus aurantium. J Chromatogr A 2007; 1161: 71-88

28 Uckoo RM, Jayaprakasha GK, Nelson SD, Patil BS. Rapid simultaneous determination of amines and organic acids in citrus using high-performance liquid chromatography. Talanta 2011; 83: 948-954

29 Ding L, Luo X, Tang F, Yuan J, Liu Q Yao S. Simultaneous determination of flavonoid and alkaloid compounds in Citrus herbs by high-performance liquid chromatography-photodiode array detection-electrospray mass spectrometry. J Chromatogr B Analyt Technol Biomed Life Sci 2007; 857: 202-209

30 He D, Shan Y, Wu Y, Liu G, Chen B, Yao S. Simultaneous determination of flavanones, hydroxycinnamic acids and alkaloids in citrus fruits by HPLC-DAD-ESI/MS. Food Chem 2011; 127: 880-885

31 Zheng GD, Zhou P, Yang H, Li YS, Li P, Liu EH. Rapid resolution liquid chromatography-electrospray ionisation tandem mass spectrometry method for identification of chemical constituents in Citri Reticulatae Pericarpium. Food Chem 2013; 136: 604-611

32 Gattuso G, Caristi C, Gargiulli C, Bellocco E, Toscano G, Leuzzi U. Flavonoid glycosides in bergamot juice (Citrus bergamia Risso). J Agric Food Chem 2006; 54: 3929-3935

33 Zhou DY, Xu Q Xue XY, Zhang FF, Liang XM. Identification of O-diglycosyl flavanones in Fructus Aurantii by liquid chromatography with electrospray ionization and collision-induced dissociation mass spectrometry. J Pharm Biomed Anal 2006; 42: 441-448

34 Shi P, He Q Song Y, Qu H, Cheng Y. Characterization and identification of isomeric flavonoid O-diglycosides from genus Citrus in negative electrospray ionization by ion trap mass spectrometry and time-of-flight mass spectrometry. Anal Chim Acta 2007; 598: 110-118

35 Avula B, Upparapalli SK, Khan IA. Simultaneous analysis of adrenergic amines and flavonoids in citrus peel jams and fruit juices by liquid chromatography: part 2. J AOAC Int 2007; 90: 633-640 